\title{
Aprendizagem profissional de gestores de federações esportivas catarinenses no ambiente educacional
}

Professional learning of catarinenses sports federation managers in the educational space

Ricardo Teixeira Quinaud

Universidade Federal de Santa Catarina, Brasil

ricardoquinaud@gmail.com

Michel Milistetd

Universidade Federal de Santa Catarina, Brasil

michel_canhoto@hotmail.com

Juarez Vieira Nascimento

Universidade Federal de Santa Catarina, Brasil

juarez.nascimento@ufsc.br

\section{Resumo:}

O estudo descritivo exploratório, de abordagem qualitativa, procurou verificar os contextos e conteúdos de aprendizagem vivenciados pelos gestores de federações esportivas catarinenses no ambiente educacional. Foram entrevistados 12 gestores de federações esportivas cujas falas foram transcritas e analisadas por meio das técnicas de análise temática. No contexto da formação inicial, enquanto que os gestores formados em Educação Física apresentaram conteúdos sobre conhecimentos técnicos da modalidade e organização de eventos, os gestores com formações em outras áreas relataram conteúdos de conceitos administrativos, relação com clientes e gestão empresarial. As regras das modalidades e a organização de competiçôes são os conteúdos frequentemente abordados no contexto dos cursos de atualização. No contexto dos cursos de pós-graduação têm contemplado conteúdos de visão empresarial, as habilidades gerenciais e as relações interpessoais. Diante das potencialidades dos contextos, recomenda-se a ampliação da oferta de disciplinas específicas de gestão esportiva na formação inicial e a oferta de cursos de mestrado profissional.

Palavras-CHAVE: Dirigente, Educação, Gestão, Desenvolvimento profissional.

\section{Abstract:}

This descriptive exploratory study has a qualitative approach and aims to verify the contexts and contents of learning experienced by the catarinenses sports federation managers in the educational space. 12 sports federation managers were interviewed, and their answers were transcribed and analyzed using thematic analysis techniques. In the undergraduate context, while graduated managers in Physical Education presented content about technical knowledge of the modality and event organization, managers graduated in other majors reported contents of administrative concepts, customer relationship, and business management. The modality rules and the competition organization are the frequent contents covered in the workshop courses. Graduate courses have contemplated content of business vision, managerial skills, and interpersonal relationships. According to the potential of the learning contexts, it is recommended to expand the offer of specific sports management disciplines in the undergraduate majors and to offer professional masters.

KEYWORDS: Director, Education, Management, Professional development.

\section{INTRODUÇÃO}

$\mathrm{Na}$ última década, o Brasil foi palco de importantes eventos esportivos internacionais que contribuíram para o fortalecimento do gestor esportivo. Além dos Jogos Olímpicos e Paralímpicos de verão em 2016, foram realizadas a décima quinta edição dos Jogos Pan-Americanos em 2007 e a vigésima edição da Copa do Mundo de Futebol em 2014. De fato, a função do gestor esportivo passou a ser vista como primordial para o sucesso destes eventos (Felix, Fernandes, \& Oliveira, 2015). Além de contribuir no gerenciamento de 
recursos humanos e financeiros (Mocsányi \& Bastos, 2005), o gestor é um profissional capaz de desenvolver o comportamento ético, transparente e responsável (Barbu \& Craciun, 2012) cuja função principal nas grandes organizações é "ajudar a realizar o potencial de outas pessoas para que elas possam ter conhecimento melhor, tomar decisões melhores e agir melhor” (p.26) (Mintzbarg, 2010).

O gestor esportivo necessita dominar competências intrínsecas a sua função (Marjoribanks \& Farquharson, 2016; Pacesa, Zakarevicius, \& Zukauskas, 2011), as quais podem ser subdivididas em dimensões comportamentais, contextuais e técnicas (Caupin et al., 2006). Em diferentes estudos que abordam as competências do gestor esportivo (Gomes, Sarmento, \& Pedroso, 2014; Joaquim, Batista, \& Carvalho, 2011; Marjoribanks \& Farquharson, 2016; Miranda, Barros Filho, Silva, Figueirêdo, \& Pedroso, 2017), as competências comportamentais (disciplina, comunicação, liderança e paciência) são as mais citadas pelos gestores, seguidas das competências contextuais (relações interpessoais, planejamento e solução de problemas) e competências técnicas (elaboração e avaliação de projetos). Apesar da identificação das competências necessárias para atuação do gestor, ainda persiste o questionamento acerca de como os gestores aprendem as competências ou qualquer conteúdo pertinente a sua prática.

As aprendizagens para intervenção futura na maioria das profissões se iniciam, de modo geral, no ambiente educacional (Illeris, 2007), principalmente nos contextos da formação inicial, dos cursos de pós-graduação e dos cursos de atualização. No Brasil, mais especificamente, a formação inicial em Educação Física aparenta ser a grande formadora dos gestores esportivos, uma vez que grande parte dos gestores possui esta formação (Amaral \& Bastos, 2015; Barros Filho et al., 2013), bem como a gestão esportiva é considerada um dos campos de intervenção do profissional de Educação Física (CONFEF, 2002). Todavia, a oferta de conteúdos desta natureza na formação inicial tem se mostrado insuficiente para garantir a atuação profissional (Bastos et al., 2006; Cárdenas \& Feuerschütte, 2015), bem como fomentado a busca de outras iniciativas de formação, como a realização de cursos de atualização e de pós-graduação. Vale ressaltar que gestores que possuem outras formações iniciais também têm ocupado postos de trabalho nesta área, entretanto em menor número.

Diante do reconhecimento social e da relevância do ambiente educacional para aprendizagem profissional de gestores esportivos, bem como da importante contribuição dos conteúdos de aprendizagem neste ambiente para melhoria da qualidade da intervenção profissional, o presente estudo foi realizado com o objetivo de verificar os contextos e os conteúdos de aprendizagem vivenciados pelos gestores de federações esportivas catarinenses no ambiente educacional.

\section{Metodologia}

O estudo caracterizou-se, quanto à sua natureza, uma pesquisa aplicada que foi implementada por meio de abordagem qualitativa (Delgado, Marín, \& Sanchez, 2011). Além disso, quanto ao seu objetivo compreendeu uma pesquisa descritiva exploratória (Gil, 2008; Thomas \& Nelson, 2002).

Fizeram parte do estudo 12 gestores de federações esportivas de oito diferentes federações do estado de Santa Catarina. Os critérios de inclusão dos participantes exigiam a atuação em federações de modalidades olímpicas, bem como estar exercendo a função de presidente, vice-presidente ou diretor. Não fizeram parte do estudo gestores que não possuíam dedicação, pelo menos, de 20 horas semanais na respectiva federação (critério de exclusão). Para preservar o anonimato dos participantes da pesquisa, as letras $\mathrm{P}$ e D foram utilizadas para identificar, respectivamente os presidentes e os dirigentes investigados.

A média de idade dos participantes da pesquisa foi de 51,6 anos (mín. 28 / máx. 67 anos), sendo 11 participantes do sexo masculino e uma do sexo feminino (D5). Todos possuem curso de graduação: oito somente em Educação Física, um em Direito (P4), um em Administração (P3), um em Turismo e Hotelaria (D2) e um em Educação Física e Contabilidade e Administração (P2). Destaca-se que quatro participantes possuem formação em nível de mestrado (P5, D1, D2 e D4). 
$\mathrm{Na}$ coleta de dados foram realizadas entrevistas abertas, porque permitem o surgimento de ideias e fenômenos inesperados que podem ser agregados a entrevista e possibilitam ao entrevistado expressar os eventos vivenciados com emoção e com mais detalhes (Sparkes \& Smith, 2014). Assim, após a conversa inicial e a explicação do significado de ambiente educacional de aprendizagem, a seguinte pergunta abrangente sobre o tema proposto pela pesquisa foi formulada: Conte-me como foram suas aprendizagens no ambiente educacional. O estudo foi aprovado pelo Comitê de Ética em Pesquisas com Seres Humanos sob o parecer no 2.143.734 e todos os participantes assinaram o Termo de Consentimento Livre e Esclarecido.

As entrevistas foram gravadas com a presença apenas do pesquisador e do entrevistado no local. Ao final do processo de coleta de dados foram transcritas 169 páginas das 12 entrevistas e com tempo médio de 57,25 minutos de entrevista gravada. Para garantir maior confiabilidades dos dados coletados e assegurar a validação das declarações, as transcrições foram reenviadas para cada um dos participantes, que puderam suprimir, adicionar ou reescrever informações que se aproximassem da real condição de aprendizagem vivenciada por eles. Além disso, o software Nvivo 9.2 foi utilizado como ferramenta auxiliar no processo de categorização e análise dos dados coletados.

Os procedimentos de análise temática, recomendados por Braun e Clarke (2006), foram empregados na etapa de análise indutiva de categorização e codificação dos dados. Após múltiplas leituras das transcrições para favorecer o processo de familiarização das entrevistas, o pesquisador iniciou a criação de uma codificação inicial, a qual foi revisada para contemplar as readequações. Após confirmação das codificações, iniciou-se o aprofundamento da interpretação dos dados codificados e a minuciosa busca por temas que poderiam ser extraídos e agrupados por similaridade das informações nelas contidas (contextos). Na sequência, a procura para identificar os temas foi iniciada. Para tanto, a releitura das falas de cada codificação foi realizada separadamente para identificação inicial dos temas congruentes e pertinentes. Em seguida, mais uma leitura foi realizada para definição dos temas e a criação das subcategorias. Após o término das etapas de codificação e categorização, a etapa de revisão dos temas foi iniciada, na qual o pesquisador relia as falas para confirmação dentro dos temas, da necessidade ou não de readequação ou até mesmo exclusão da fala. Com o pesquisador satisfeito com o agrupamento dos temas, a definição, a nomeação e a verificação da necessidade de cada tema foram implementadas. Além disso, o pesquisador relia as falas para verificação da relevância de cada uma delas de acordo com o objetivo proposto pelo estudo. Por fim, a última etapa foi marcada pela transmissão dos dados a partir de sua validade e confiabilidade durante todo o seu processo de análise até o leitor.

Os procedimentos de confirmação "intrapesquisador" e "interpesquisador" foram empregados para garantir maior rigor e confiança ao processo de análise de dados (Gibbs, 2009). Enquanto que a confirmação "intrapesquisador" foi operacionalizada a partir da revisão das interpretações pelo investigador principal após o intervalo de uma semana, a confirmação "interpesquisador" foi obtida a partir do confronto das interpretações entre dois pesquisadores.

\section{Resultados}

As informações obtidas, a partir das falas dos gestores, foram organizadas de acordo com os contextos e os conteúdos de aprendizagem no ambiente educacional (Figura 1). Os contextos identificados foram a formação inicial, subdividida em formação em Educação Física e outras formações, os cursos de atualização e os cursos de pós-graduação, cada contexto com os respectivos conteúdos de aprendizagem. 
FIGURA 1

Contextos e conteúdos de aprendizagem dos gestores esportivos no ambiente educacional.

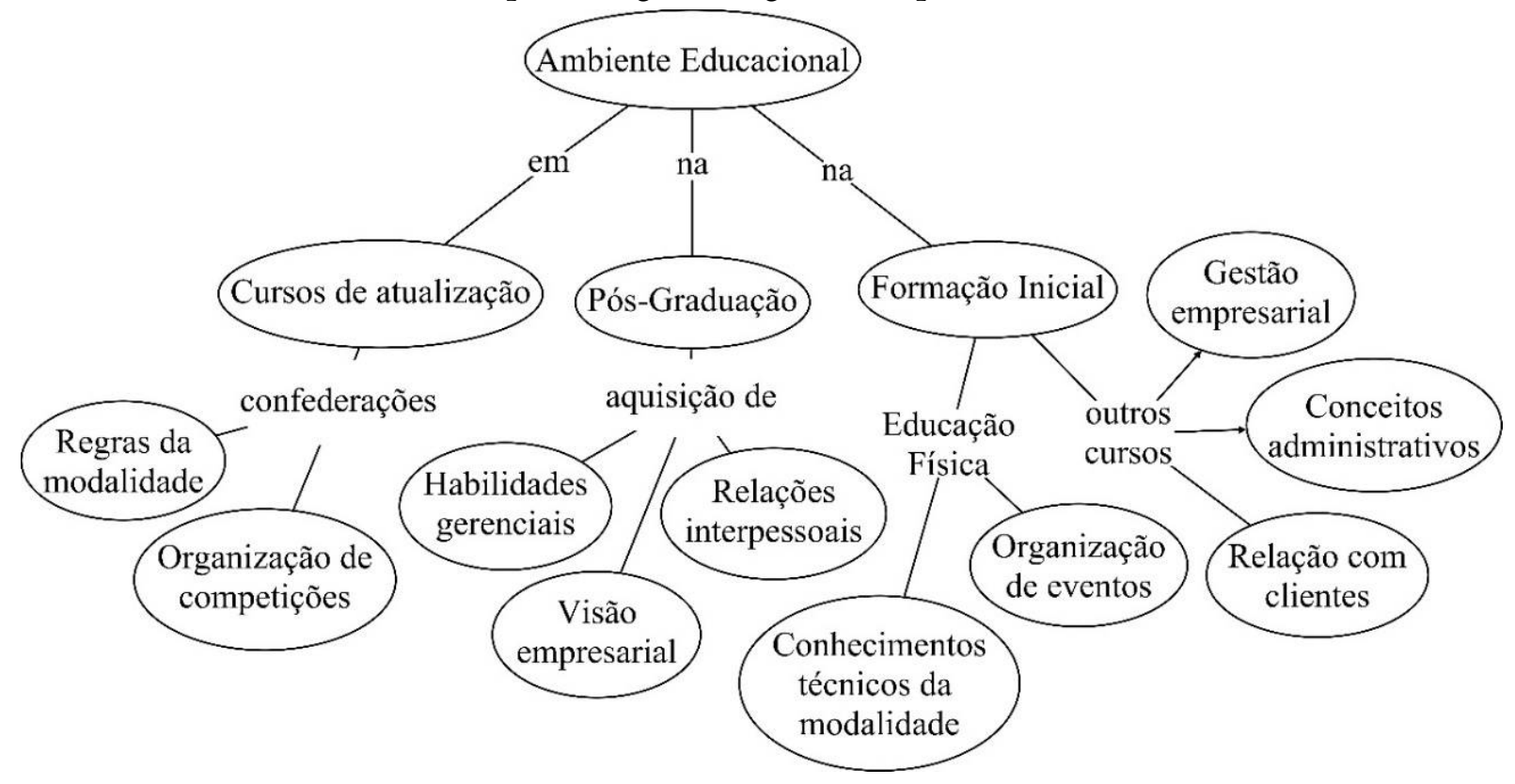

Fonte: Dados da pesquisa.

No que diz respeito ao contexto da formação inicial em Educação Física, emergiram das falas os conteúdos de conhecimentos técnicos da modalidade e organização de eventos, sendo este último o que mais se aproxima das funções e atribuições do gestor esportivo nas federações. O gestor P2, por possuir três formações iniciais, comentou que a formação em Educação Física auxilia com conteúdos técnicos inerentes à Educação Física (conhecimentos biomecânicos, fisiológicos e regras da modalidade) para a preparação das competições (provas): "Na parte da Educação Física eu trago o conhecimento técnico. Certas nuances da prova você vai elaborar no papel para depois executar na prática". Na fala de D5 foi identificada a presença de um currículo generalista e que a disciplina de Organização de Eventos foi a única que mais se aproximou de sua atuação na federação: “[...] na graduação a gente tem sempre uma visão geral. Para a gestão da federação, por exemplo, eu acho que

nsegue aplicar dentro da federação". De maneira semelhante, D4 relatou que o curso não ofertou disciplinas relacionadas à Gestão do Esporte e que, para ele, a disciplina de Organização de Eventos seria a que mais se aproximaria do contexto da gestão: “[...] nós não temos nenhuma disciplina além da organização de eventos, que é passado brevemente como é que pode ser pensando um evento. Não é pensado gestão do esporte lá dentro".

Apesar de alguns gestores investigados elencarem conteúdos de aprendizagem que consideram relevantes para sua atuação profissional, mesmo com determinadas ressalvas ao currículo da formação inicial em Educação Física, outros gestores foram enfáticos na falta de oportunidades de aprendizagem neste contexto de formação. Para D3, o curso de graduação serviu apenas para conseguir o diploma e que suas aprendizagens se concentram no seu dia-a-dia na organização: “[...] a faculdade só te deu um canudo, o que tu aprendeste foi no dia-a-dia”. Não obstante, P1 argumentou que sua formação não proporcionou aprendizagens relacionadas à gestão do esporte: “[...] hoje estou meio perdido quanto à Educação Física, mas a formação em Educação Física não me ajudou muito”.

Os gestores que realizaram formação inicial em outras áreas relataram conteúdos de aprendizagem que contemplam a relação com clientes, conceitos administrativos e gestão empresarial. O gestor D2 comentou que as aprendizagens de sua formação acadêmica foram relevantes para aquisição de conhecimentos financeiros e relação com clientes: "Voltado para o lado acadêmico da minha formação, talvez a questão 
financeira, que eu acho que é importante. E outra eu vejo que é a questão de relação com o cliente”. O gestor P3 enfatizou as aprendizagens em administração, as quais são praticadas tanto na vida pessoal quanto na federação esportiva: "Na parte administrativa, que você aprendeu na faculdade tu pratica na tua gestão e aqui na parte administrativa de toda federação". Já para P4, as aprendizagens em advocacia empresarial têm auxiliado na gestão da federação: "[...] e advocacia empresarial ela automaticamente está voltada para gestão. Então, as noções de administração, as noções de gestão a gente têm".

Em relação ao contexto de cursos de atualização, os gestores investigados ressaltaram a preocupação com a atualização e aprimoramento contínuos de seus conhecimentos, bem como a relevância dos cursos promovidos pelas respectivas confederações das modalidades, principalmente pela elevada aproximação com a realidade das organizações esportivas. Contudo, P5 comentou que poucos cursos conseguem fornecer o suporte necessário para atuação: “[...] é uma formação prática. Poucos cursos me deram este suporte”. Apesar de enfrentar dificuldades na aplicação dos conhecimentos obtidos nos cursos de atualização, porque frequentemente os conhecimentos abordados não correspondem ou atendem as demandas da realidade na qual está inserido, P1 reconhece que a nova aprendizagem contribuiu no alcance de novas ideias para implementação e adaptação de ações efetivas:

"O que eu aprendi com os cursos ano após ano que eu fazia era o que não adiantava você fazer curso de um padrão alto se tinha uma realidade $\mathrm{X}$, uma realidade baixa. $\mathrm{O}$ que me ensinou foi que eu fiz curso, alguns cursos, e quando eu fui trazer aquilo para minha realidade não deu certo, mas me ajudaram a adaptar para minha realidade".

Um aspecto ressaltado pelos gestores investigados é que as regras da modalidade e a organização de competições são os conteúdos de aprendizagem frequentemente abordados nos cursos de atualização ofertados pelas confederações. Sobre este assunto, P3 relatou que os cursos ofertados pela confederação de sua modalidade compreendem importantes oportunidades para aprendizado diferente do habitual, especialmente para atualização das regras da modalidade: “[...] a única aprendizagem que a gente tem são as vezes cursos que a confederação participa com a gente, é um aprendizado diferente. Fora disso não tem outro segmento onde tu vais aprender sobre regras da modalidade [...]”. Além disso, D3 atribuiu ao curso ofertado por sua confederação a aprendizagem sobre a organização de competições: "[...] a gente fez um curso de uns 3-4 dias. Lá a gente aprendia como fazer uma competição acontecer e como fazer ela a avaliação da competição em si. Então ali que a gente começou a aprender alguma coisa sobre competição".

Os cursos de pós-graduação lato sensu e stricto sensu compreendem o terceiro contexto identificado no ambiente educacional de aprendizagem, o qual emergiu de forma tímida nas falas dos investigados. As iniciativas desta natureza têm sido acrescentadas às aprendizagens advindas da formação inicial e das respectivas atuações profissionais, destacando-se os conteúdos de visão empresarial, habilidades gerenciais e relações interpessoais. Ao ser questionado sobre a realização de cursos de gestão esportiva, o gestor D2 argumentou que as aprendizagens obtidas nos cursos de pós-graduação, em nível de mestrado e de especialização em Administração, foram somadas a sua experiência como atleta e têm auxiliado na gestão da respectiva federação:

"Eu fiz MBA e fiz dois mestrados. Um mestrado inclusive fiz fora. Primeiro fiz MBA em Administração Global. Fiz mestrado em Gestão Estratégica das Empresas e em Direção de Gestão Turística na Espanha. Então, todos os conteúdos são voltados para Administração de Empresas. Então, todos eles de alguma forma ajudaram nesta minha formação, para que somada a minha formação de atleta eu conseguisse ter esta visão empresarial da modalidade e habilidades administrativas para isso".

O gestor P5, que também realizou cursos de especialização e mestrado, enfatizou que gestão esportiva é lidar com os outros e que sua formação continuada tem auxiliado a melhor se relacionar com os pares:

Fiz duas especializações, Educação Infantil e Administração Esportiva e vim fazer o mestrado quase no fim de carreira. Então, isso tudo somado, a gente aprende a lidar com os outros. E administrar é lidar com os outros. O principal da administração é saber lidar com os outros. Que o trabalho em si ele rola, as finanças a gente têm que saber equilibrar para tocar, mas lidar com os outros é muito complicado. 


\section{Discussão}

Os gestores investigados apontaram a incipiência de conteúdos relacionados a gestão esportiva na formação inicial em Educação Física para suportar a intervenção profissional nesta área, destacando também a importância da oferta da disciplina de organização de eventos e das disciplinas que contemplam conteúdos técnicos da respectiva modalidade (biomecânicos, fisiológicos e regras da modalidade). Apesar da presença marcante de disciplinas com este último conteúdo nos currículos de Bacharelado em Educação Física, uma vez que esta formação está voltada principalmente aos conhecimentos biológicos do corpo humano e conhecimentos técnicos-instrumentais de avaliação e treinamento físico (Pizani \& BarbosaRinaldi, 2014), os conteúdos de gestão esportiva ainda estão em fase de reconhecimento nos currículos e compreendem importantes lacunas de formação (Mazzei, Amaya, \& Bastos, 2013).

Um aspecto a destacar é que as mudanças nas diretrizes curriculares da área de Educação Física têm favorecido a oferta de cursos de Bacharelado em Educação Física, minimizando assim a fragilidade de um currículo generalista experimentado por alguns gestores investigados, cuja trajetória formativa foi operacionalizada em ambientes institucionalizados no século passado. Apesar dos conteúdos relacionados a gestão do esporte terem o seu espaço aumentado gradativamente nos currículos de cursos desta natureza (Montagner, Scaglia, \& Amaya, 2012), ainda permanece a necessidade de aperfeiçoar as disciplinas que abordem conteúdos de gestão nas grades curriculares (Bastos et al., 2006) assim como de minimizar o problema de baixa oferta de disciplinas de gestão (Cárdenas \& Feuerschütte, 2015).

Outro ponto a considerar é que a aprendizagem em ambientes institucionalizados, de acordo com Illeris (Illeris, 2007), tem ocorrido muitas vezes em situação isolada do mundo real, o que pode justificar a falta de oportunidades de aprendizagem neste contexto de formação apontada pelos gestores investigados. Ao limitar a aprendizagem somente no ambiente institucionalizado, ela dificulta a transferência de aprendizagens para outros contextos bem como favorece o aparecimento do choque de prática quando os estudantes forem usar suas aprendizagens educacionais fora deste ambiente. Neste sentido, Illeris (Illeris, 2007) acredita que deva haver uma reestruturação, tanto emocional quanto em termos de conteúdo, antes dos conteúdos de aprendizagem serem aplicados fora do contexto institucional. Além disso, uma possibilidade para aproximar os dois campos (teórico e prático) seria desenvolver atividades que avaliem os estudantes no saber fazer, e não somente no saber intrínseco de cada conteúdo de aprendizagem (Bedwell, Fiore, \& Salas, 2014).

Outra dificuldade enfrentada para se estabelecer maior integração entre os cursos de formação com o contexto prático de intervenção profissional é que os professores estão frequentemente inclinados a pensar e agir em termos de currículo, enquanto que os supervisores do local de trabalho pensam e atuam em termos de processos de trabalho e produção (Illeris, 2009). De fato, embora estejam lidando com o mesmo serviço (esporte), os dois grupos têm grandes problemas para aceitar e entender as abordagens de cada um. Assim, além de buscar maior diálogo e aproximação entre os ambientes de formação e de trabalho, o aprimoramento da formação inicial perpassa pela melhor fundamentação das disciplinas ofertadas, com maior adequação à realidade e às perspectivas da área no próprio país (Bastos, 2004).

Com relação aos gestores formados em outras áreas, o contexto da formação inicial parece ter contribuído positivamente para suas funções nas federações, uma vez que expressam conteúdos de aprendizagem voltados à gestão, conceitos administrativos e relação com clientes, os quais compreendem competências necessárias para atuação do gestor esportivo (Gomes et al., 2014; Joaquim et al., 2011). E, diferentemente dos gestores formados somente em Educação Física, eles parecem enfrentar menos dificuldades na aplicação dos conteúdos de aprendizagem da formação inicial com o contexto prático de intervenção profissional no esporte. Entretanto, apesar da relevância destas aprendizagens para atuação destes gestores na federação, em determinadas situações poderão ser associados ou confundidos com a figura pejorativa do "cartola" (Mazzei \& Rocco Júnior, 2017). Além de manifestarem "ter uma visão empresarial da modalidade", conforme 
mencionado pelo gestor D2, eles são oportunistas que gerenciam o esporte como um mero negócio para benefício próprio, desvirtuando as particularidades e as características da gestão esportiva.

No que diz respeito ao contexto dos cursos de atualização, os gestores investigados apontaram a relevância dos cursos ofertados pelas respectivas confederações esportivas, que contemplam as regras das modalidades e a organização de competições. No entanto, ressaltaram a baixa oferta de cursos direcionados à gestão do esporte. A procura por cursos considerados corporativos (confederações) pode indicar a tentativa dos gestores de suprirem as carências da temática de gestão esportiva em suas formações iniciais, bem como revelar a preocupação com o aprimoramento de conhecimentos para favorecer suas ações e tomadas de decisões (Mazzei \& Rocco Júnior, 2017).

As dificuldades enfrentadas na aplicação das novas aprendizagens oriundas dos cursos de atualização acompanham a discrepância apontada pelos gestores investigados entre as realidades vivenciadas nas respectivas federações e aquela abordada no curso. Independentemente das distintas realidades vivenciadas em cada federação, as lacunas da formação inicial e as aprendizagens anteriores também podem estar afetando a compreensão dos gestores. De fato, as novas aprendizagens são frequentemente julgadas a partir das aprendizagens passadas, podendo ser consideradas positivas quando já possua conhecimento ou negativas caso não tenham conhecimento (Belzer, 2004).

Quanto ao contexto dos cursos de pós-graduação, os gestores investigados destacaram a importância de cursos desta natureza pela aquisição de habilidades e competências. Ao aproximarem os conteúdos e as atividades das aulas com as experiências profissionais dos estudantes, os cursos de pós-graduação têm auxiliado no desenvolvimento sistemático de competências (Ruas \& Comini, 2007). Além disso, este contexto de formação é considerado um momento relevante na vida das pessoas, no qual a reflexão se faz presente e pode promover transformações pessoais inerentes ao contexto social (Conklin, Kyle, \& Robertson, 2012).

Apesar da maioria dos cursos de pós-graduação realizados pelos gestores investigados não ser na área de gestão do esporte, a relevância está associada à oportunidade de aquisição de competências genéricas, como autoconhecimento, comunicação escrita, planejamento de trabalho, confiança, entre outros (Jackson, 2014). Essas competências são essenciais para distintos postos de trabalho, seja nas federações esportivas ou em outras organizações, porque as habilidades consideradas imprescindíveis são similares (Hinchliffe \& Jolly, 2011). Entretanto, as competências específicas para a função somente serão adquiridas ao longo da vida, a partir da execução das atividades gerenciais rotineiras e cotidianas (Bridgstock, 2009).

Um aspecto importante não mencionado pelos gestores investigados diz respeito às oportunidades limitadas de formação continuada nos cursos de mestrados acadêmicos e profissionais. Além da baixa presença de áreas de concentração e linhas de pesquisa que contemplem temáticas específicas da gestão esportiva nos mestrados acadêmicos, a oferta de cursos de mestrado profissional é bastante limitada para melhor qualificar as competências específicas dos gestores, pois o único curso de mestrado profissional que atendia as demandas da área no Brasil foi descontinuado em 2016 (Mazzei \& Rocco Júnior, 2017).

Os cursos de mestrado profissional auxiliam na prática profissional avançada (Brasil, 2009), cuja contribuição para melhoria da qualidade dos profissionais tem sido reconhecida por distintas áreas de conhecimento (Maciel \& Nogueira, 2012; Martins \& Ribeiro, 2013; Miranda, Novaes, \& Avelar, 2013; Pilatti et al., 2015; Vilela \& Batista, 2015). Entretanto, a oferta de cursos desta natureza na área da gestão esportiva está bastante atrasada no Brasil. Nos países em que o mestrado profissional em gestão do esporte já é estruturado, observa-se o aumento da qualidade da intervenção profissional e do capital financeiro promovido pelo esporte (Pitts \& Stotlar, 2002). Vale ressaltar que aumentar o capital financeiro não significa utilizar o esporte apenas como objetivo mercadológico, mas indica o quanto o esporte consegue impactar na vida das pessoas. 


\section{Conclusão}

Considerando o objetivo do estudo em identificar os contextos e os conteúdos de aprendizagem profissional de gestores de federações esportivas catarinenses no ambiente educacional de aprendizagem, as evidências revelaram três contextos inerentes ao ambiente educacional, nomeadamente a formação inicial, os cursos de atualização e os cursos de pós-graduação lato sensu e stricto sensu, cada um com seus conteúdos. No contexto da formação inicial, enquanto que os gestores formados em Educação Física apresentaram conteúdos semelhantes sobre conhecimentos técnicos da modalidade e a organização de eventos, os gestores com formações em outras áreas relataram conteúdos similares de conceitos administrativos, relação com clientes e gestão empresarial. A carência de disciplinas que abordam conteúdos relacionados a gestão do esporte foi ressaltada somente pelos gestores formados em Educação Física.

No que diz respeito ao contexto dos cursos de atualização, as oportunidades formativas restringem-se aos cursos ofertados pelas confederações, que abordam conteúdos de regras das modalidades e a organização de competições. Por fim, a pós-graduação, mesmo maneira tímida, apareceu como terceiro contexto, no qual a aquisição de visão empresarial, as habilidades gerenciais e as relações interpessoais compreendem os principais conteúdos de aprendizagem.

Apesar das evidências do estudo revelarem as potencialidades de distintos contextos no ambiente educacional, algumas mudanças são necessárias para assegurar a aprendizagem mais significativa dos gestores esportivos, especialmente na formação inicial e nos cursos de pós-graduação stricto sensu. Além da ampliação da oferta de disciplinas específicas de gestão esportiva na formação inicial, com a realização de estágio curricular, recomenda-se a oferta de cursos de mestrado profissional em gestão esportiva para fortalecer as competências específicas assim como melhor qualificar a atuação profissional na área.

Diante das limitações do estudo, especialmente a utilização de uma única fonte de informação sobre os contextos investigados, sugere-se que futuros estudos utilizem abordagens mais robustas para aprofundar a análise nesta temática e neste campo investigativo, bem como contemplem a análise conjunta das trajetórias formativas, esportivas e profissionais de gestores esportivos.

\section{REFERÊNCIAS}

Amaral, C. M. d. S., \& Bastos, F. d. C. (2015). O gestor esportivo no Brasil: revisão de publicações no país. Revista Intercontinental de Gestão Desportiva, 5(1), 68-78.

Barbu, M. C. R., \& Craciun, L. (2012). Considerations on managerial ethics in sports organizations. Management \& Marketing Journal, 10(1), 59-68.

Barros Filho, M. A., Pedroso, C. A. M. Q., Fatta, G. L., Luiggi, G., Lima, G. A., Henrique, W., Silva, T. C. A., \& Rocha, V. L. S. (2013). Perfil do gestor esportivo Brasileiro: uma revisão de literatura. Revista Intercontinental de Gestão Desportiva, 3.

Bastos, F. C. (2004). Administração Esportiva: área de estudo, pesquisa e perspectivas no Brasil. Motrivivência, 15(20-21), 295-306.

Bastos, F. C., Barhum, R. A., Alves, M. V., Bastos, E. T., Mattar, M. F., Rezende, M. F., Mardegan, M., \& Bellangero, D. (2006). Perfil do administrador esportivo de clubes de São Paulo/Brasil. Revista Mackenzie de Educação Física e Esporte, 5(1), 13-22.

Bedwell, W. L., Fiore, S. M., \& Salas, E. (2014). Developing the future workforce: An approach for integrating interpersonal skills into the MBA classroom. Academy of Management Learning \& Education, 13(2), 171-186.

Belzer, A. (2004). "It's not like normal school": The role of prior learning contexts in adult learning. Adult Education Quarterly, 55(1), 41-59. doi: https://10.1177/0741713604268893

Brasil, (2009). Portaria normativa no 7 de 22 d ejunho de 2019. Dispõe sobre o mestrado profissional no âmbito da Fundação Coordenação de Aperfeiçoamento de Pessoal de Nível Superior - CAPES. 
Braun, V., \& Clarke, V. (2006). Using thematic analysis in psychology. Qualitative research in psychology, 3(2), 77-101. Bridgstock, R. (2009). The graduate attributes we've overlooked: Enhancing graduate employability through career management skills. Higher Education Research \& Development, 28(1), 31-44.

Cárdenas, A. R., \& Feuerschütte, S. G. (2015). A gestão na formação inicial em educação física: um olhar qualitativo sobre currículos, disciplinas e ementas dos cursos de bacharelado de Santa Catarina. Criar Educação, 4(1), 10-26.

Caupin, G., Knoepfel, H., Koch, G., Pannenbäcker, K., Pérez-Polo, F., \& Seabury, C. (2006). ICB - IPMA Competence Baseline (Vol. Version 3.0). Netherlands: International Project Management Association.

CONFEF, (2002). Resolução n. 46, de 18 de fevereiro de 2002. Dispõe sobre a Intervenção do Profissional de Educação Física e respectivas competências e define os seus campos de atuação profissional. Rio de Janeiro, 18 de fevereiro de 2002. Disponível em: http://www.confef.org.br/extra/resolucoes/conteudo.asp?cd_resol=82 . Acesso em: 11 abril 2017.

Conklin, J., Kyle, T., \& Robertson, C. (2012). The essential transformation: How Masters students make sense and learn through transformative change. Management Learning, 44(2), 161-178.

Delgado, S. C., Marín, B. M., \& Sanchez, J. R. (2011). Métodos de investigación y análisis de datos em ciencisa sociales y de la salud. España: Pirámide.

Felix, C. A. F., Fernandes, A. S., \& Oliveira, P. W. S. (2015). Competências gerenciais da equipe do comitê organizador dos jogos Pan-Americanos Rio 2007. Catussaba - Revista Cientifica da Escola da Saúde, 4(3), 19-26.

Gibbs, G. R. (2009). Análise de dados Qualitativos. Porto Alegre: Artmed.

Gil, A. C. (2008). Métodos e Técnicas de Pesquisa Social (6 Ed. ed.). São Paulo: Atlas.

Gomes, J. L. d. B., Sarmento, J. P., \& Pedroso, C. A. M. Q. (2014). Competências, perfil e formação do gestor esportivo de academia de ginástica: uma revisão. Resvista Intercontinental de Gestão Desportiva, 4(1), 99-112.

Hinchliffe, G. W., \& Jolly, A. (2011). Graduate identity and employability. British Educational Research Journal, 37(4), 563-584.

Illeris, K. (2007). How we Learning: learning and non-learning in school and beyond. New York: Routledge.

Illeris, K. (2009). Transfer of learning in the learning society: How can the barriers between different learning spaces be surmounted, and how can the gap between learning inside and outside schools be bridged? International Journal of Lifelong Education, 28(2), 137-148.

Jackson, D. (2014). Skill mastery and the formation of graduate identity in Bachelor graduates: evidence from Australia. Studies in Higher Education, 41(7), 1313-1332.

Joaquim, B. A., Batista, P. M., \& Carvalho, M. J. (2011). Revisão Sistemática sobre o perfil de competências do gestor desportivo. Movimento, 17(1), 255.

Maciel, R. G. A., \& Nogueira, H. G. P. (2012). Mestrado profissional: desenvolvimento pessoal e profissional. Revista Brasileira de Pós-Graduação, 9(17), 461-487.

Marjoribanks, T., \& Farquharson, K. (2016). Contesting competence Chief executive officers and leadership in Australian Football League clubs. Marketing Intelligence \& Planning, 34(2), 188-202. doi: https://10.1108/m ip-09-2014-0171

Martins, R. X., \& Ribeiro, C. M. (2013). Mestrado profissional em Educação e inovação na prática docente. Revista Brasileira de Pós-Graduação, 10(20), 423-446.

Mazzei, L. C., Amaya, K., \& Bastos, F. C. (2013). Programas acadêmicos de graduação em gestão do esporte no Brasil. Revista Mackenzie de Educação Física e Esporte, 12(1), 219-234.

Mazzei, L. C., \& Rocco Júnior, A. J. (2017). Um ensaio sobre a Gestão do Esporte: Um momento para a sua afirmação no Brasil. Revista de Gestão e Negócios do Esporte, 2(1), 96-109.

Mintzbarg, H. (2010). Managing: desvendando o dia a dia da gestão. Porto Alegre: Bookman.

Miranda, M. G., Novaes, A. M. P., \& Avelar, K. E. S. (2013). Mestrado profissional interdisciplinar em desenvolvimento local: uma proposta inovadora. Revista Brasileira de Pós-Graduação, 10(20), 451-474. 
Miranda, Y. d. H. B., Barros Filho, M. A., Silva, V. H. R., Figueirêdo, J. d. M. C., \& Pedroso, C. A. M. Q. (2017). Análise acerca das competências necessárias para a atuação profissional do gestor esportivo. Pensar a Prática, 20(3), 593-603.

Mocsányi, V., \& Bastos, F. C. (2005). Gestão de pessoas na administração esportiva: considerações sobre os principais processos. Revista Mackenzie de Educação Física e Esporte, 4(4), 55-69.

Montagner, P. C., Scaglia, A. J., \& Amaya, K. G. (2012). Desafios da formação em esporte para intervenção profissional no contexto da gestão: investigações iniciais. In J. V. Nascimento \& G. O. Farias (Eds.), Construção da identidade profissional em Educação Física: da formação à intervenção. Florianópolis: UDESC.

Pacesa, N., Zakarevicius, P., \& Zukauskas, P. (2011). The profile of Lithuanian manager. Problems and Perspectives in Management, 9(1), 59-70.

Pilatti, L. A., Morais Costa, J., Schirlo, A. C., Silva, S. d. C. R., Pinheiro, N. A. M., \& Frasson, A. C. (2015). Mestrado profissional em Ensino de Matemática: identificação de seus produtos educacionais. Revista Brasileira de PósGraduação, 12(28), 335-356.

Pitts, B., \& Stotlar, D. (2002). Fundamentos de marketing esportivo. São Paulo: Phorte.

Pizani, J., \& Barbosa-Rinaldi, I. P. (2014). Identidade dos cursos de licenciatura e bacharelado em Educação Física no Paraná: uma análise das áreas do conhecimento. Revista Brasileira de Educação Física e Esporte, 28(4), 671-682.

Ruas, R., \& Comini, G. M. (2007). Aprendizagem e desenvolvimento de competências: articulando teoria e prática em programas de pós-graduação em formação gerencial. Cadernos EBAPE. br, 5(SPE), 01-14.

Sparkes, A. C. \& Smith, B. (2014). Qualitative Research Methods in Sport, Exercise and Health: from the process tro product. Abingdon: Routledge.

Thomas, J. \& Nelson, J. (2002). Métodos de pesquisa em atividade física. Porto Alegre: Artmed.

Vilela, R. B., \& Batista, N. A. (2015). Mestrado Profissional em Ensino na Saúde no Brasil: avanços e desafios a partir de políticas indutoras. Revista Brasileira de Pós-Graduação, 12(28), 307-331. 